\title{
Dermatological disorders in Tuvalu between 2009 and 2012
}

\author{
LI-JUNG LAN ${ }^{1,2}$, YING-SHUANG LIEN ${ }^{2,3}$, SHAO-CHUAN WANG ${ }^{2,4}$, NESE ITUASO-CONWAY ${ }^{5}$, \\ MING-CHE TSAI ${ }^{2,6}$, PAO-YING TSENG ${ }^{6}$, YU-LIN YEH $^{1}, \mathrm{CHUN}^{-T Z U ~ C H E N}{ }^{7}$, \\ KO-HUANG LUE ${ }^{2,8}$, JING-GUNG CHUNG ${ }^{9,10}$ and YU-PING HSIAO ${ }^{1,2}$
}

\begin{abstract}
${ }^{1}$ Department of Dermatology, Chung Shan Medical University Hospital, Taichung 40201; ${ }^{2}$ Institute of Medicine, School of Medicine, Chung Shan Medical University, Taichung 40201; Departments of ${ }^{3}$ Obstetrics and Gynecology, and ${ }^{4}$ Urology, Chung Shan Medical University Hospital, Taichung 40201; ${ }^{5}$ Public Health, Princess Margaret Hospital, Ministry of Health, Funafuti, Tuvalu; ${ }^{6}$ International Medical Service Center, Chung Shan Medical University Hospital, Taichung 40201; Departments of ${ }^{7}$ Chief Secretary Group and ${ }^{8}$ Pediatrics, Chung Shan Medical University Hospital, Taichung 40201; ${ }^{9}$ Department of Biological Science and Technology, China Medical University, Taichung 40201; ${ }^{10}$ Department of Biotechnology, Asia University, Taichung 41354, Taiwan, R.O.C.
\end{abstract}

Received July 1, 2014; Accepted September 18, 2014

DOI: $10.3892 / \mathrm{mmr} .2015 .3806$

\begin{abstract}
There is a distinct lack of knowledge on the prevalence of skin disorders in Tuvalu. The aim of the current study was to assess the prevalence of cutaneous diseases and to evaluate access dermatological care in Tuvalu. Cutaneous disorders in the people of Tuvalu between 2009 and 2012 were examined. The most common skin conditions were eczema/dermatitis, superficial fungal infections, impetigo, carbuncles, furuncles, folliculitis, acne, scabies, warts and keloids. Infrequent skin conditions included infectious granulomatous disease, albinism, actinic keratosis, skin cancer, cutaneous lupus erythematosus and mammary Paget's disease, which required medical attention. This is the first epidemiological report on skin disorders in the southwest Pacific Island, Tuvalu.
\end{abstract}

\section{Introduction}

Tuvalu is a Polynesian Island nation consisting of nine islands and reefs, located in the southwest Pacific Ocean (latitude, $5-10^{\circ}$ south; longitude $176-179^{\circ}$ east) (1). The distance from Tuvalu's capital (Funafuti) to Fiji's capital (Suva) is $\sim 1,100 \mathrm{~km}$, and about 4,200 km from Funafuti to Sydney (1). The national

Correspondence to: Professor Jing-Gung Chung, Department of Biological Science and Technology, China Medical University, 91 Hsueh-Shih Road, Taichung 40201, Taiwan, R.O.C.

E-mail: jgchung@mail.cmu.edu.tw

Professor Yu-Ping Hsiao, Department of Dermatology, Chung Shan Medical University Hospital, 110, Sec. 1, Chien-Kuon Road, Taichung 40201, Taiwan, R.O.C.

E-mail: skin.csmu@gmail.com

Key words: Tuvalu, dermatological disorders, epidemiology land area of Tuvalu is only $25.9 \mathrm{~km}^{2}$, and the highest point does not exceed $4 \mathrm{~m}$ above sea level (1). Currently, an estimated 11,000 people live in Tuvalu (1). The Taiwan International Cooperation and Development Fund (Taiwan ICDF) has coordinated the medical resources of Taiwanese hospitals in order to provide long-term medical assistance to eight countries in the Pacific Ocean: Marshall Islands, Kiribati, Solomon Islands, Palau, Nauru, Tuvalu, Papua New Guinea and Fiji (2). Based on the Mobile Medical Missions, in 2009 Chung Shan University Hospital sent dermatologists to Tuvalu. There is little information on the skin conditions of the Tuvalu population. The aim of the current study was to determine the most common skin diseases and to assess access to dermatological care in a sample of Tuvaluan individuals.

\section{Subjects and methods}

Patients. All patients presenting with skin disorders between 2009 and 2012 in Tuvalu (332 patients; age range, 1-76 years old), were assessed for skin diseases via a complete dermatological examination. All participants were asked about any previous skin diseases, other medical conditions and family history. Diagnosis of various cutaneous conditions was based on characteristic clinical features. In certain instances, the diagnosis of superficial fungal infections was confirmed by a potassium hydroxide assay $(3,4)$. The study was approved by the Ethics Committee of Chung Shan Medical University Hospital (Taichung, Taiwan, R.O.C.; CS 14137), and written informed consent was obtained where required.

\section{Results}

Dermatological diseases in Tuvalu. Among the 332 patients, $177(53.3 \%)$ were females and 155 (46.7\%) were males, with an average age of $30.2 \pm 6.3$ years. Frequently observed skin conditions included pruritus, excoriations, scratching, painful wounds, unhealed ulcers, skin discoloration, acne and keloids. The most common dermatological diseases and 
Table I. The most common dermatological diseases in Tuvalu.

\begin{tabular}{lrr}
\hline Disease & $\mathrm{n}$ & $\%$ \\
\hline Infectious diseases & & \\
$\quad$ Superficial fungal infections & 114 & 34.3 \\
Impetigo & 72 & 21.7 \\
Carbuncles and furuncles & 56 & 16.9 \\
Folliculitis & 37 & 11.1 \\
Cellulitis & 31 & 9.3 \\
Scabies & 48 & 14.4 \\
Verruca & 25 & 7.5 \\
Inflammatory diseases & & \\
Eczema & 125 & 37.7 \\
Prurigo nodularis & 41 & 12.3 \\
Acne & 52 & 15.6 \\
Intertrigo & 32 & 9.6 \\
Miscellanies & & \\
Keloids & 18 & 5.4 \\
\hline
\end{tabular}

Total patients $(\mathrm{n}=332)$.

Table II. Infrequent dermatological diseases requiring medical assistance.

Disease

No. of patients

Infectious diseases

Infectious granulomatous disease

Inflammatory diseases

Discoid lupus erythematosus

Malignancies

Mammary Paget's disease

Squamous cell carcinoma

Actinic keratosis

Miscellanies

Albinism

Vitiligo

Neurofibromas

1

Port-wine stain

their respective prevalence were as follows: Eczema/dermatitis $(37.7 \%)$, superficial fungal infections (34.3\%), impetigo (21.7\%), carbuncles and furuncles (16.9\%), folliculitis $(11.1 \%)$, cellulitis $(9.3 \%)$, acne $(15.6 \%)$, prurigo nodularis $(12.3 \%)$, intertrigo (9.6\%), scabies $(14.4 \%)$, warts $(7.5 \%)$ and keloids $(5.4 \%)$ as presented in Table I. Eczema/dermatitis included atopic dermatitis, seborrheic dermatitis, contact dermatitis, dyshidrotic eczema, summer eczema, nummular eczema, stasis dermatitis and lichen simplex chronicus. Superficial fungal infections included tinea capitis, tinea barbae, tinea corporis,

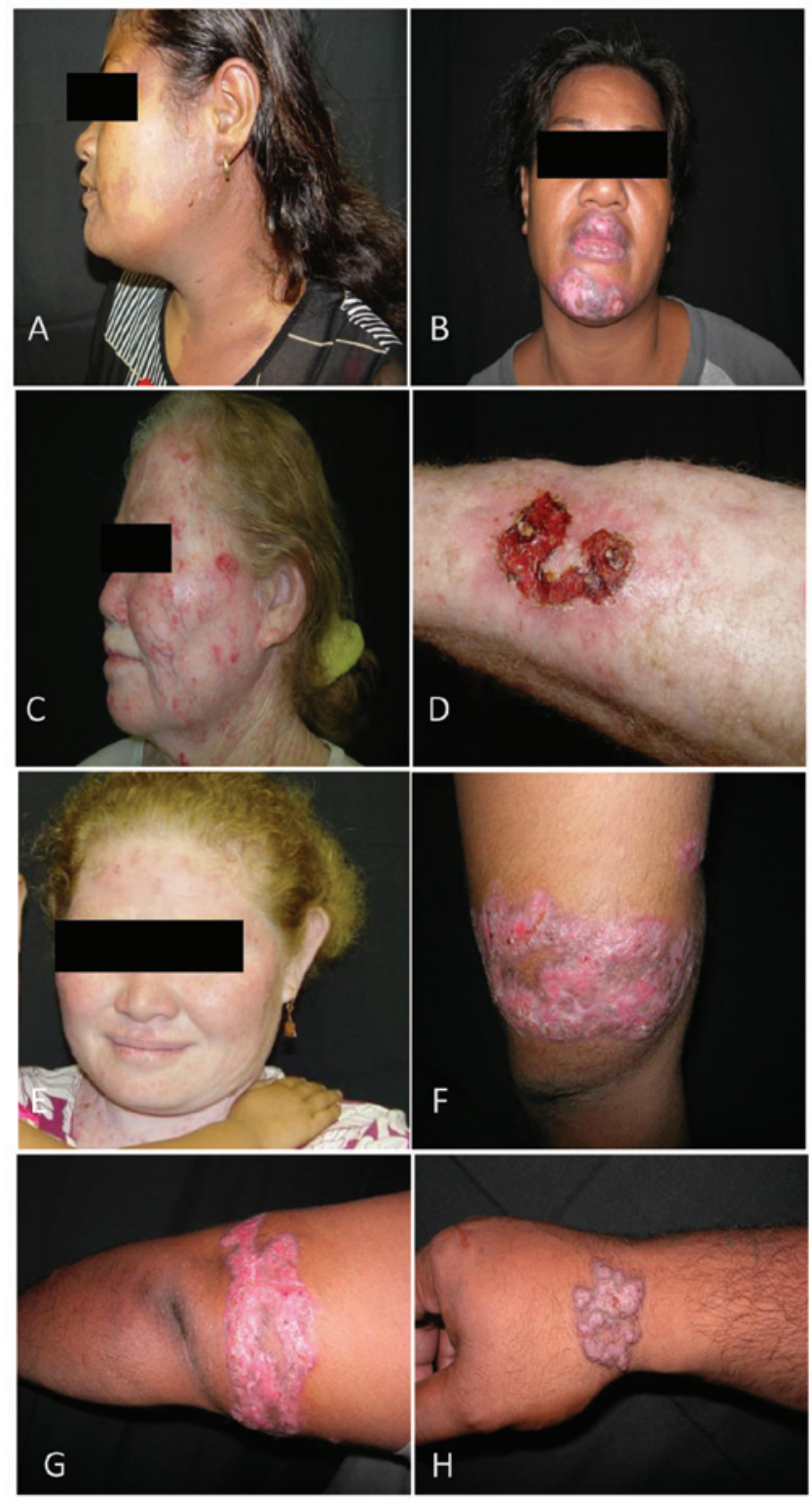

Figure 1. Infrequent dermatological diseases requiring medical assistance. (A) A 25-year-old female with a port-wine stain. (B) A 39-year-old female with discoid lupus erythematosus over the lips and chin. (C) A 57-year-old female with albinism. (D) A 57-year-old female with albinism and skin cancers over the right leg. (E) A 27-year-old patient with albinism. (F) A 26-year-old male with infectious granulomatous disease over the right thigh. (G) A 26-year-old male with infectious granulomatous disease over the left arm. (H) A 25-year-old male with infectious granulomatous disease over the right wrist.

tinea cruris, tinea mamuum, tineapedis, onychomycosis and mucocutaneous candidiasis. Infrequent skin conditions listed in Table II included port-wine stain (Fig. 1A), discoid lupus erythematosus (Fig. 1B), vitiligo, mammary Paget's diseases, albinism (Fig. 1C-E), actinic keratosis, squamous cell carcinoma and infectious granulomatous diseases (Fig. 1F-H), which all required medical treatment.

\section{Discussion}

This report is the first epidemiological study to investigate the prevalence of dermatological diseases in Tuvalu. Leppäniemi (5-8) has reported on several surgical proce- 
dures and surgical cases in Tuvalu between 1990-1993. Nelesone et al (9) established a successful African outbreak surveillance model for poliomyelitis, cholera, diarrhoea, dysentery, typhoid, measles, meningococcalmeningitis and outbreaks of febrile diseases of unknown origin, which may provides a basis for a potential model for use in Tuvalu (9). However, medical staff and access to care were inadequate in the past.

In Tuvalu, the climate is usually hot and hygiene is poor due to the lack of a clean water supply. The majority of the population collect rainwater from the roofs of buildings and store it for daily use (1). Skin infections are a common health problem in Tuvalu, as well as in other Pacific island nations (10). Superficial fungal infections and scabies were found in 34.3 and $14.4 \%$ of individuals in Tuvalu respectively, and the ratio of scabies was similar to that observed in the population of Tanna in Vanuatu (10). The results of the current study are in agreement with Steer et al (11) in that the most common skin problems in children in Fiji were infected scabies $(22.2 \%)$, impetigo (20.2\%), non-infected scabies $(9.7 \%)$ and abscesses or localized cellulitis $(8.1 \%)$. Following the introduction of crotamiton lotion and/or permethrin cream, the incidence of scabies in Tuvalu has been observed by the authors of the current study to be in decline. In addition, the present study determined that following education on the treatment of skin wounds (avoiding contact with seawater), other infectious diseases, such as impetigo, carbuncles, furuncles and cellulitis were cured with short courses of amoxicillin or cephalosporin.

The rare but important issue was the observation of infectious granulomatous diseases in Tuvalu. Skin biopsy, histopathology and tissue culture were not available, and so the diagnosis of these granulomatous diseases was difficult. Tuvalu's predominant diseases are tuberculosis, leprosy and parasitic infections (1). Four non-endemic cases in patients from Pacific Islands are described to have chromoblastomycosis caused by Fonsecaea pedrosoi (12). Chromoblastomycosis, deep fungal infection, leprosy, tuberculosis cutis or sarcoidosis must be included in the differential diagnosis in these patients with granulomatous diseases (Fig. 1F-H).

In the current study, a number of patients with albinism suffered from severe photosensivities, actinic keratosis and skin cancer (Fig. 1E-G). Similar issues have been described in Africa (12). This is particularly problematic for individuals with albinism living in tropical countries with intense UV exposure, and these individuals are negatively impacted emotionally and physically from dermatological malignancies (13-15). Variants of the MC1R gene in patients with oculocutaneous albinism increased susceptibility to skin cancer (14). Frequent skin evaluations should be performed, in addition to education for patients regarding sun protection.

This study is the first epidemiological report of skin disorders in Tuvalu. Future studies are required, in which clinical assessments are made and current treatment approaches are evaluated.

\section{Acknowledgements}

The authors would like to thank the Medical Project in the Pacific Island Countries and Mobile Medical Missions supported by the Taiwan International Cooperation and Development Fund (Taiwan ICDF) and the Chung Shan Medical University Hospital (Taiwan). The authors would like to acknowledge the epidemiological information provided by the Bureau of Consular Affairs, Ministry of Foreign Affairs, Republic of China (Taiwan), and would like to recognise the help from Dr Nese Ituaso, Dr Stephen Homasi, Mr. Pelesala Kaleia, and the medical team from the Princess Margaret Hospital (Tuvalu).

\section{References}

1. Tuvalu demographics. Bureau of Consular Affairs, Ministry of Foreign Affairs, Republic of China (Taiwan). http://www.boca. gov.tw/ct .asp? Item $=829 \&$ ctNode $=753 \& \mathrm{mp}=1$ (In Chinese). Accessed March 24, 2015.

2. Medical Project in the Pacific Island Countries. Taiwan International Cooperation and Development Fund (TaiwanICDF) http://www.icdf.org.tw/np.asp?ctNode=29872\&mp=2. Accessed March 24, 2015.

3. Sasmaz S Celik M: Skin diseases in Turkish soldiers. Dermatol Sinica 29: 44-46, 2011.

4. Yamamoto T, Hung WC, Takano T and Nishiyama A: Genetic nature and virulence of community-associated methicillin-resistant Staphylococcus aureus. BioMedicine 3: 2-18, 2013.

5. Leppäniemi AK: Surgery in Tuvalu: a 10-year review. Aust N Z J Surg 60: 373-376, 1990.

6. Leppäniemi AK: Intravesical foreign body after inguinal herniorrhaphy. Case report. Scand J Urol Nephrol 25: 87-88, 1991.

7. Leppäniemi AK: Where there is no anaesthetist... Br J Surg 78: 245-246, 1991.

8. Leppäniemi AK: Obstetrics and the general surgeon. Surg Gynecol Obstet 176: 365-367, 1993.

9. Nelesone T, Durrheim DN, Speare R, Kiedrzynski T and Melrose WD: Short communication: Strengthening sub-national communicable disease surveillance in a remote Pacific Island country by adapting a successful African outbreak surveillance model. Trop Med Int Health 11: 17-21, 2006.

10. Harris M, Nako D, Hopkins T, et al: Skin infections in Tanna, Vanuatu in 1989. P N G Med J 35: 137-143, 1992.

11. Steer AC, Tikoduadua LV, Manalac EM, et al: Validation of an integrated management of childhood illness algorithm for managing common skin conditions in Fiji. Bull World Health Organ 87: 173-179, 2009.

12. Woodgyer AJ, Bennetts GP and Rush-Munro FM: Four non-endemic New Zealand cases of chromoblastomycosis. Australas J Dermatol 33: 169-176, 1992.

13. Cruz-Inigo AE, Ladizinski B and Sethi A: Albinism in Africa: stigma, slaughter and awareness campaigns. Dermatol Clin 29: 79-87, 2011.

14. Sengupta M, Sarkar D, Mondal M, et al: Analysis of MC1R variants in Indian oculocutaneous albinism patients: highlighting the risk of skin cancer among albinos. J Genet 92: 305-308, 2013.

15. de Vijlder HC, de Vijlder JJ and Neumann HA: Oculocutaneous albinism and skin cancer risk. J Eur Acad Dermatol Venereol 2012. 